\title{
A educação intercultural e os desafios para a escola e para o professor*
}

\author{
The intercultural education and the challenges for school and teacher
}

L'éducation interculturel et les défis pour l'école et l'enseignant

\author{
La educación intercultural y los desafíos para la escuela y el maestro \\ Vanilda Alves da Silva** \\ Flavinês Rebolo***
}

Recebido em 02/02/2017; revisado e aprovado em 06/02/2017; aceito em 06/02/2017

DOI: http:/ / dx.doi.org/10.20435/1984-042X-2017-v.18-n.1(14)

\begin{abstract}
Resumo: $\mathrm{O}$ artigo discute os desafios enfrentados pelos professores frente às diferenças culturais que permeiam a escola contemporânea. Realizado a partir de uma revisão bibliográfica, traz as principais dificuldades para a escola e para o professor quando se busca uma educação pautada em princípios de igualdade e respeito pelo diferente, que caminhe na perspectiva do diálogo e que considere o 'outro' relevante.

Palavras-chave: educação intercultural; escola contemporânea; professores.

Abstract: The article discusses the challenges faced by teachers against the cultural differences that permeate contemporary school. Conducted from a literature review, presents the main difficulties for the school and the teacher when it seeks a guided education on principles of equality and respect for the different, to walk in the dialogue perspective and to consider the 'other' relevant. Key words: intercultural education; contemporary school; teachers.

Résumé: L'article décrit les défis confrontés par les enseignants devant les différences culturelles qui imprègnent l'école contemporaine. Menée à partir d'une revue bibliographique, présente les principales difficultés pour l'école et l'enseignant lorsque se cherche une éducation fondée dans des principes d'égalité et respect par le différent, que marcher dans la perspective de dialogue et d'envisager l'«autre» pertinente.

Mots-clés: éducation interculturelle ; ecole contemporaine ; les enseignants.

Resumen: El artículo analiza los desafíos que enfrentan los maestros en contra de las diferencias culturales que permean la escuela contemporánea. Realizado a partir de una revisión de la literatura, presenta las principales dificultades para la escuela y el maestro cuando se busca una educación guiada en principios de igualdad y el respeto al diferente, al caminar en la perspectiva de diálogo y tener en cuenta el "otro" relevante.

Palabras clave: educación intercultural; escuela contemporánea; profesores.
\end{abstract}

\section{INTRODUÇÃO}

Este artigo apresenta alguns dos desafios colocados aos professores pelas diferenças culturais que permeiam a escola contemporânea. É resultado do levantamento bibliográfico e das primeiras reflexões realizadas para a pesquisa intitulada Trabalho e bem-estar de professores Guarani de Matemática em escolas indígenas, que tem por objetivo analisar as possibilidades de construção do bem-estar docente para os professores Guarani, da disciplina de matemática, que trabalham em escolas indígenas.

A discussão sobre a educação intercultural é uma necessidade para a sociedade que, cada vez mais, traz à tona

\footnotetext{
* Este artigo é uma versão revista e ampliada do trabalho "A educação intercultural no âmbito da escola", apresentado no VI Povos Indígenas e Sustentabilidade - Saberes indígenas e a contemporaneidade / I Seminário do Observatório da Educação - Educação Escolar Indígena (OBEDUC/CAPES/UCDB), na Universidade Católica Dom Bosco. Campo Grande, MS, 2015.

** Universidade Federal de Mato Grosso do Sul (UFMS), Campo Grande, Mato Grosso do Sul, Brasil.

*** Universidade Católica Dom Bosco (UCDB), Campo Grande, Mato Grosso do Sul, Brasil.
} 
seu caráter multicultural e onde "diferentes grupos socioculturais conquistam maior presença nos cenários públicos" (CANDAU, 2011, p. 241), incluindo aí a escola. Nas escolas contemporâneas, já estão presentes discussões sobre questões étnicas, raciais, de gênero etc., mas, ainda, de forma incipiente e não suficiente para evitar tensões e conflitos. Trata-se de questão complexa que afeta o cotidiano das escolas e o trabalho dos professores.

As reflexões que se seguem buscam contribuir para o entendimento dos desafios colocados por uma "escola necessária”, pautada em princípios de igualdade e respeito pelo diferente, mas para a qual os professores nem sempre estão preparados, considerando que foram formados para trabalhar em uma escola que prioriza o homogêneo e o uniforme, que considera o "diferente" como um "problema a ser resolvido", conforme afirma Candau (2011, p. 241).

\section{A EDUCAÇÃO INTERCULTURAL: OS DESAFIOS PARA A ESCOLA}

Somos todos iguais ou somos todos diferentes? Queremos ser iguais ou queremos ser diferentes? Houve um tempo que a resposta se abrigava segura de si no primeiro termo da disjuntiva. Já faz um quarto de século, porém, que a resposta se deslocou. A começar da segunda metade dos anos 70, passamos a nos ver envoltos numa atmosfera cultural e ideológica inteiramente nova, na qual parece generalizar-se, em ritmo acelerado e perturbador, a consciência de que nós, os humanos, somos diferentes de fato [...], mas somos também diferentes de direito. É o chamado 'direito da diferença', o direito à diferença cultural, o direito de ser, sendo diferente. The right to be different!!!, como se diz em inglês, o direito à diferença. Não queremos mais a igualdade, parece. Ou a queremos menos, motiva-nos muito mais, em

\begin{abstract}
nossa conduta, em nossas expectativas de futuro e projetos de vida compartilhada, o direito de sermos pessoal e coletivamente diferentes uns dos outros. (PERUCCI, 1999, p. 7).
\end{abstract}

A escola atual, inserida em uma sociedade que se transforma rapidamente e que está marcada fortemente por movimentos que combatem as desigualdades em todos os sentidos, se vê frente a grandes desafios para que possa realizar, de fato, uma educação intercultural e cumprir seu papel social na construção de uma sociedade mais justa, igual e solidária. Como afirma Candau (2008, p. 2) a partir de estudos com Maciel et al., a educação intercultural "aparece como uma perspectiva alternativa e contra-hegemônica de construção social, política e educacional, sendo complexa por estar atravessada por desafios e tensões, tornando necessária a problematização das diferentes práticas sociais e educativas".

Esses desafios e tensões são apontados por Candau (2008) a partir da análise dos artigos publicados na Revista Brasileira de Educação, nos anos de 2008 a 2012. A autora ressalta, em suas análises, as principais discussões sobre essa temática à luz das diferentes abordagens do multiculturalismo e da interculturalidade e, embora constate o pequeno número de textos que abordam a diferença cultural, encontra questões significativas e desafiadoras, tanto para as sociedades, quanto para a escola atual e, em particular, para os processos educacionais e as práticas pedagógicas. Dentre eles se destacam: questões de gênero, sexualidade, relações étnico-raciais, tensões entre igualdade e diferenças e direitos humanos. A maior parte dos textos analisados por Candau (2008) são de reflexão teórica e analítica a respeito da interculturalidade e do multiculturalismo, e um número bem menor de pesquisas voltadas para o "chão da escola". 
A discussão referente à construção das identidades de sujeitos invisibilizados, ou não valorizados, na sociedade atual é necessária no sentido de melhor compreender e possibilitar a promoção da igualdade de oportunidades e a integração dos diferentes sujeitos socioculturais na sociedade em que vivemos. Mas, ainda que seja possível verificar um avanço na escola atual, no que diz respeito às práticas escolares e às diferenças cultural, também é necessário e relevante promover o estímulo para produção de mais trabalhos que abordem temáticas relacionadas às práticas escolares e ao trabalho dos professores em uma perspectiva que contemple a diversidade cultural.

Pesquisadores como Candau (2008, 2009, 2011), Fleuri (2002, 2003), entre outros, discutem que, para que a educação intercultural aconteça, é necessário que o professor reflita e vivencie, ativamente, a diversidade dos grupos sociais, étnicos, religiosos, culturais etc. Candau (2009, p. 170) afirma que

[...] a educação intercultural não pode ser reduzida a algumas situações e/ou atividades realizadas em momentos específicos, nem focalizar sua atenção exclusivamente em determinados grupos sociais. Trata-se de um enfoque global que deve afetar todos os atores e todas as dimensões do processo educativo, assim como os diferentes âmbitos em que ele se desenvolve. No que diz respeito à escola, afeta a seleção curricular, a organização escolar, as linguagens, as práticas didáticas, as atividades extraclasse, o papel do/a professor/a, a relação com a comunidade etc.

Esses aspectos apontados por Candau mostram a necessidade de muitas mudanças no sistema educativo, tanto no âmbito estrutural como no desenvolvimento de competências de gestores e professores, para que se alcance uma educação que possibilite a convivência de diferentes grupos culturais.

Considerando que o papel da escola não deve ser apenas o de transmitir um determinado conhecimento, mas que é, também, o de se comprometer com atitudes que favorecem a produção e a (re) significação dos saberes e dos conhecimentos dos diferentes grupos culturais, vale ressaltar que os debates e discussões que possam favorecer a busca e as lutas por justiça social, por reconhecimento e por melhores condições humanas de vida para todos, indistintamente, devem ser o eixo norteador da educação que se pretende atualmente.

As diferenças culturais devem estar "dentro da escola" como parte integrante das relações interpessoais e das práticas pedagógicas no âmbito do ambiente escolar, e é nesse caminho que se deve pensar as ações educativas. Ações essas que permitam o aprendizado dos diferentes sujeitos, grupos, sociedades e que respeitem e valorizem as diversidades culturais. Isso orientará a construção de uma sociedade democrática, plural, humana, que articule políticas de igualdade com políticas de identidade. (CANDAU, 2009, 2011; FLEURI, 2002).

Fleuri (2002, p. 11) considera que

[...] a perspectiva intercultural implica uma compreensão complexa de educação, que busca - para além das estratégias pedagógicas e mesmo das relações interpessoais imediatas - entender e promover lenta e prolongadamente a formação de contextos relacionais e coletivos de elaboração de significados que orientam a vida das pessoas.

Por isso torna-se imprescindível que se abram, no âmbito escolar, além das discussões sobre as práticas pedagógicas interculturais, espaços para o debate de temas que envolvam as preocupações, as tensões, os conflitos, as tentativas de diálogo e negociações relativas às diferenças 
culturais em âmbito geral, para que promovam a conquista de maior presença dos diferentes grupos socioculturais nos múltiplos cenários públicos.

Silva e Almeida (2012) nos alertam para os cuidados que se deve ter frente ao tratamento e discussão dessas questões no âmbito escolar, pois

A forma como a desigualdade deve ser tratada na educação, tende a dissociá-la da desigualdade social e econômica, supondo que há diferentes desigualdades, de tal modo que se deveria cuidar para que o esforço de combater o mau tratamento da diferença na educação não acentue a disparidade da combinação de desigualdade de classe com formas de discriminação baseada na negação do direito à diversidade. (SILVA; ALMEIDA, 2012, p. 35).

Diante dessa posição, é possível verificar a urgência de se reconhecer e de se valorizar as diferenças, uma vez que se tornam indispensáveis e essenciais na dinâmica das escolas. Ressalta-se a importância da dimensão cultural como forma de potencializar processos de aprendizagem mais significativos e produtivos para todos os sujeitos envolvidos no âmbito escolar, com questões e discussões referentes aos seus direitos.

Desde a institucionalização da escola pública, têm-se dificuldades de trabalhar com as diferenças. Candau (2011), apoiada em Lerner, afirma que a escola do século XX, pública, gratuita e obrigatória, recebeu historicamente uma herança do século anterior, que se trata de criar um único povo, uma única nação, com indivíduos considerados iguais perante a lei, no entanto desconsiderando as suas diferenças socioculturais. A intenção foi nivelar igualdade à homogeneidade. Nesse sentido, se os indivíduos legalmente eram tidos como iguais, logo a escola deveria colaborar para gerar esses indivíduos, no sentido de homogeneizar as crianças, sem considerar suas origens diferentes. Dessa forma, essa escola não podia aceitar diferenças, tendo em vista que ela se incumbiu de igualar os sujeitos que dela participam.

A escola contemporânea carrega esse histórico dos séculos anteriores, de tratar todos de forma homogênea. E, nesse contexto, segundo Candau (2008), a partir das ideias de Lerner, chama a atenção para a necessidade de oferecer à escola mecanismos didáticos no sentido de que possibilitem seu trabalho com a diversidade e, além disso, aponta que se torna imprescindível que a escola possua ao menos materiais didáticos/pedagógicos que viabilizem trabalhar com a diversidade, transformando a diversidade conhecida e reconhecida em benefício pedagógico, o que parece ser o grande desafio do futuro.

Para Candau (2011) essa é a direção que deverá ser seguida para a concretização de uma escola democrática e justa, no sentido de promover a igualdade sem negar a diferença. A autora considera que

[...] a dimensão cultural é intrínseca aos processos pedagógicos, "está no chão da escola" e potencia processos de aprendizagem mais significativos e produtivos, na medida em que reconhece e valoriza a cada um dos sujeitos neles implicados, combate todas as formas de silenciamento, invisibilização e/ou inferiorização de determinados sujeitos socioculturais, favorecendo a construção de identidades culturais abertas e de sujeitos de direito, assim como a valorização do outro, do diferente, e o diálogo intercultural. (CANDAU, 2011, p. 253).

É possível verificar que o grande desafio da escola permeia o desenvolvimento de um trabalho com a diversidade e sua transformação em aliados pedagógicos, ou seja, uma escola que se proponha a atuar de forma ativa com a heterogeneidade, no sentido de legitimar as diferenças, ou seja, de valorizar outro. 
Serpa (2011) partilha da mesma ideia e chama atenção para a necessidade de se pensar um outro modelo de escola,

[...] que seja fruto não de um projeto iluminado, de modelos importados, ou de soluções miraculosas. Mas uma escola tecida por uma rede de saberes, onde o aprendizado não seja apenas um objetivo final a ser alcançado, mas o próprio percurso percorrido. Defendo uma escola pensada não para sujeitos, mas pelos sujeitos. [...] Sujeito que não vive e que não narra sozinho, mas que traz consigo - e em si - as muitas vozes e suas experiências que narram também. (SERPA, 2011, p. 154-155).

Serpa mostra a importância de se pensar uma escola que reconheça, além dos sujeitos, os seus caminhos, e que, principalmente, se permita que esses sujeitos participem ativamente do pensar e da construção dessa escola. É necessário, no âmbito escolar, dialogar com as diferenças, ouvir a voz do(s) outro(s), uma vez que

[...] ao desqualificar o outro, sua voz, seus saberes, seus conhecimentos, sua percepção do mundo, esvazio qualquer sentido que possa existir na defesa do diálogo. Esvazio qualquer sentido que possa haver na palavra "democracia". Esvazio qualquer sentido [...] que tenha a diferença como valor. Diferença entendida aqui como este profundo respeito e consciência da existência do outro da legitimidade de seu lugar no mundo, respeito que me permite, mesmo no conflito, mesmo na disputa, instaurar um espaço de negociação, ouvir o outro, e neste processo, ouvir-me através do outro. (SERPA, 2011, p. 165).

A escola tem a função relevante de (re)conhecer, dar valor e poder a todos os sujeitos socioculturais, no sentido de reconhecer a diferença cultural como expressão positiva. Para tanto, a escola deve realizar um trabalho que vise ao desenvolvimento de ações que dialoguem com diversos conhecimentos e saberes, diferentes linguagens, distintas estratégias e recursos pedagógicos, entendendo a relevância de promover o reconhecimento das diferenças sociais, de defender e buscar os direitos, de evitar preconceito e discriminação, enfim, de tornar a escola um lugar plural.

Ainda frente às questões referentes às diferentes funções da escola numa nova perspectiva, Gabriel (2006, p. 39) afirma que, no final dos anos 90, “[...] não bastava mais lutar apenas contra as desigualdades sociais, no âmbito da instituição escolar, tornava-se necessário também buscar estratégias pedagógicas onde as diferenças culturais pudessem coexistir de forma democrática".

A escola por si só não dará conta de enfrentar esses desafios e realizar seu papel, se ela não contar com meios para esse fim, ou seja, mecanismos que possibilitem e contribuam para a realização dos objetivos no sentido de dirimir as diferenças.

Candau (2011, p. 253) afirma que estamos distantes de "instrumentalizar didaticamente a escola" no sentido de trabalhar com as diferenças, bem como de transformá-las em "vantagem pedagógica", mas entende que estamos caminhando nessa direção e que

[...] nós, professoras e professores de didática e das demais disciplinas dos cursos de formação destes profissionais também estamos desafiados a trabalhar nesta direção, não somente teoricamente, mas incorporando esta perspectiva nas nossas próprias práticas pedagógicas. (CANDAU, 2011, p. 253).

E é nesse contexto que a autora espera e acredita numa educação e numa escola que caminhe na perspectiva do diálogo, que considere relevante o 'outro', que 
valorize o diferente, legitimando, assim, a perspectiva intercultural e a promoção de uma educação que, por meio do diálogo, procura reconhecer diferentes grupos sociais e culturais e que "[...] enfrenta os conflitos provocados pela assimetria de poder entre os diferentes grupos socioculturais nas nossas sociedades e é capaz de favorecer a construção de um projeto comum, pelo qual as diferenças sejam dialeticamente integradas" (CANDAU, 2011, p. 52).

Alguns desafios perpassam a educação numa perspectiva intercultural, em que seja possível uma reconstrução, no sentido de penetrar no universo de preconceitos e discriminações o qual impregna as relações sociais que configuram os contextos que vivemos e caminhe para uma ressignificação dos direitos humanos e para uma concepção intercultural das políticas emancipatórias.

A interculturalidade como um "um processo dinâmico e permanente de relação, comunicação e aprendizagem entre culturas em condições de respeito, legitimidade mútua, simetria e igualdade", também é um intercâmbio

\begin{abstract}
[...] que se constrói entre pessoas, conhecimentos, saberes e práticas culturalmente diferentes, buscando desenvolver um novo sentido entre elas na sua diferença; um espaço de negociação e de tradução onde as desigualdades sociais, econômicas e políticas, e as relações e os conflitos de poder da sociedade não são mantidos ocultos e sim reconhecidos e confrontados; uma tarefa social e política que interpela o conjunto da sociedade, que parte de práticas e ações sociais concretas e conscientes e tenta criar modos de responsabilidade e solidariedade; e uma meta a alcançar. (CANDAU, 2011, p. 10-11).
\end{abstract}

Candau (2011) ainda afirma que, mesmo com a introdução da perspectiva intercultural implantada nas reformas educativas em vários países latino-americanos, "não há um entendimento comum sobre as implicações pedagógicas da interculturalidade, nem até que ponto nelas se articulam as dimensões cognitiva, procedimental e atitudinal; ou o próprio, o dos outros e o social" (CANDAU, 2011, p. 12).

\section{A EDUCAÇÃO INTERCULTURAL: DESAFIOS PARA O PROFESSOR E O TRABALHO DOCENTE}

\author{
A docência envolve o professor em \\ sua totalidade; sua prática é re- \\ sultado do saber, do fazer e princi- \\ palmente do ser, significando um \\ compromisso consigo mesmo, com o \\ aluno, com o conhecimento e com a \\ sociedade e sua transformação. \\ (GRILLO, 2004, p. 78)
}

A complexidade da educação intercultural é grande e coloca muitos desafios à escola contemporânea, como esboçado acima e, também, grandes desafios ao professor e ao seu trabalho. A seguir, explicitam-se alguns desses desafios colocados aos professores.

O trabalho docente, segundo Tardiff e Lessard (2011), é um conceito que envolve a execução de tarefas pré-estabelecidas, além de outras que ocorrem no cotidiano escolar sem que estivessem previstas, por meio de relações interpessoais entre professores, alunos e outros atores da escola. Os autores classificam o trabalho docente como um trabalho interativo, na medida em que só é possível de ser realizado a partir da comunicação entre professor e aluno e, como ocorre em todo processo de comunicação, as diferenças individuais (socioculturais, crenças, valores, interesses, etc.) estão presentes e determinam a maneira como esse processo se concretiza.

Além do aspecto interacional, ao se discutir o professor e seu trabalho, é preciso considerar, também, o local em que esse trabalho é realizado. A estrutura organizacional da escola, o "modo como 
o trabalho é organizado, controlado, segmentado, planejado, etc" (TARDIFF; LESSARD, 2011, p. 49) condicionarão os modos de ser e estar na profissão dos professores e as diversas maneiras de se realizar a atividade de ensinar que, segundo os autores, pode ser definida como o "agir na classe e na escola em função da aprendizagem e da socialização dos alunos atuando sobre a capacidade de aprender, para educá-lo e instruí-los com a ajuda de programas, métodos, livros, exercícios, normas, etc."

Assim, tanto as relações estabelecidas no âmbito da escola (entre professores, alunos e demais trabalhadores, destes com o produto do trabalho, com os objetivos, recursos, saberes e resultados do trabalho), como o local (infraestrutura, gestão e recursos materiais) determinarão as formas de se conduzir o processo ensino e aprendizagem e os modos de trabalhar do professor.

Há, ainda, um outro aspecto com o qual, segundo Jesus (2007), o professor precisa lidar atualmente, qual seja:

[...] as implicações decorrentes da massificação do ensino e da excessiva exigência política colocada sobre o trabalho do professor; as alterações ocorridas na estrutura e dinâmica das famílias do acelerado desenvolvimento tecnológico; e conteúdos transmitidos pela mídia. (JESUS, 2007, p. 17).

A ocorrência dessas transformações sociais, tanto quanto as questões relacionais e de estrutura organizacional, podem gerar grandes conflitos e desafios para o professor. E, quando esses desafios são por demais complexos e estão além da capacidade de enfrentamento dos professores, pode ocorrer o adoecimento e/ou o mal-estar docente e o fracasso do processo de ensino e aprendizagem.

As transformações sociopolíticas que norteiam a atuação dos docentes na atualidade deram um novo sentido para a escola e para o trabalho do professor, que atua com muitas formas de diversidade ao realizar seu trabalho. Conforme afirmam Sá e Cortez (2012, p. 2), "o entendimento e discussão de saberes multi/ interculturais ao cotidiano educativo faz-se indispensável e coloca-se como um dos desafios contemporâneos ao trabalho docente". As autoras entendem que

[...] a mediação de saberes multi/ interdisciplinares no processo educativo é uma necessidade, já que a especificidade dos contextos em que se educa hoje ganha cada vez mais importância, e dessa forma o/a professor/a e a escola, não deve só se adequar a essas novas demandas, mas, sobretudo, fazer uma releitura da sua visão de educação, desenvolver uma nova sensibilidade a partir de saberes interculturais que promova no diálogo as diferentes culturas desconstruindo a ideia de educação monocultural. (SÁ; CORTEZ, 2012, p. 2).

Fleuri (2003, p. 26), citando um estudo realizado por Gilberto Ferreira da Silva, também destaca a importância do diálogo na prática docente para o enfrentamento dos conflitos gerados pelas diferenças. Segundo ele,

A escola constitui-se em território de enfrentamentos invisíveis, onde as diferenças são marcadas por aspectos visíveis como a deficiência física, o vestuário (indicador de pertencimento a uma classe social), as práticas religiosas, o sexo e a cor da pele. Alunos e professores vivenciam tais conflitos e encaminham soluções, na maioria das vezes sem a busca por uma compreensão de âmbito maior. Nesse sentido, o autor propõe a perspectiva da educação intercultural como estratégia para potencializar a própria ação desencadeada pelo conflito, mediante o diálogo e o encontro, de modo que constitua espaços alternativos produtores 
de outras formas de identidades, marcadas pela fluidez, pela interação e pela acolhida do diferente. (FLEURI, 2003, p. 26).

O estabelecimento desse diálogo e do encontro com o outro diferente é um grande desafio para os professores que, na maioria das vezes, são formados para uma educação monocultural. Jesus (1998) afirma que a formação é a unidade essencial para a melhor atuação profissional e deverá ter como foco um processo de formação "orientado para o desenvolvimento de qualidades pessoais e interpessoais que possam contribuir para uma prática de ensino personalizada e para o sucesso profissional do professor" e da educação (JESUS, 1998, p. 41).

Os desafios colocados por uma proposta de educação intercultural, que considere as especificidades dos contextos onde ocorre o processo de ensino e aprendizagem, mostram a importância de uma formação que capacite o professor a conduzir sua prática de forma a atender as diversas culturas que permeiam o espaço escolar, "partindo do pressuposto de que entre alunos/as e educadores/as possa se estabelecer o diálogo intercultural tendo em vista uma educação inclusiva e democrática" (SÁ; CORTEZ, 2012, p. 7).

Realizar esse diálogo intercultural imprime um novo ritmo ao trabalho docente e exige a ressignificação de práticas pedagógicas consolidadas no âmbito de paradigmas vigentes desde a sociedade industrial. Para Candau (2002, p. 53), “a cultura escolar predominante nas nossas escolas se revela como 'engessada', pouco permeável ao contexto em que se insere, aos universos culturais das crianças e jovens a que se dirige e a multiculturalidade das nossas sociedades". Desconstruir o caráter 'engessado' e homogeneizador dessas práticas e reconstruir propostas de trabalho inovadoras, contextualizadas e com ênfase na diversidade é outro grande desafio para os professores.
Grande desafio colocado aos professores que, em última instância, são responsabilizados e cobrados por essa reconstrução. Nesse sentido, Coppete (2012, p. 526) pergunta: "estaria faltando sensibilidade aos professores e professoras que insistem em homogeneizar o que é desde a sua constituição diverso? Segundo a autora, não parece ser apenas esta a questão, pois

\section{[...] a realidade nos mostra a expressiva anestesia que afeta a todos e todas. Professores e pro- fessoras não estão isentos; pelo contrário: talvez sejam algumas das pessoas mais frontalmente abaladas pelos seus efeitos. As condições de trabalho, a formação inicial e continuada, os contextos das escolas, entre outros tantos fatores que envolvem toda a com- plexidade da própria docência e do viver têm contribuído para afastar e anestesiar a sensibilida- de do cotidiano. (COPPETE, 2012, p. 526-527).}

É preciso, então, um esforço conjunto de todos os envolvidos no sistema educacional para que o professor consiga desenvolver práticas pedagógicas interculturais.

Segundo Gasparin (2007, p. 6), “essa nova forma pedagógica de agir exige que se privilegiem a contradição, a dúvida, o questionamento; que se valorizem a diversidade e a divergência [...]", que se compreendam os conhecimentos em suas múltiplas faces, que se vise à participação ativa do aluno, que se considere o meio em que os alunos vivem e que se valorize o conhecimento e a cultura que esses educandos trazem para a escola. Isto não parece tarefa fácil para os professores, especialmente se foram formados dentro de uma perspectiva de educação monocultural, com práticas homogeneizadoras, que desconsideram as diferenças.

[...] entretanto, sabemos que é no ambiente escolar, mais 
especificamente dentro da sala de aula, que o professor, enquanto mediador e organizador dos conhecimentos terá o poder de mediar a construção das mais diversas representações construídas pelo seu aluno através das mais variadas atividades e recursos pedagógicos que utiliza em sala, já que as categorias de representação de identidade e diferença carregam um peso simbólico muito forte enquanto atividades que constroem e desconstroem significados. (SÁ; CORTEZ, 2012, p. 16).

Para que esse poder e a mediação dos professores em sala de aula se concretizem e resultem, de fato, na construção e reconstrução de significados, e quiçá em respostas às questões sobre o fracasso e o êxito escolar, sobre o direito à diferença e à igualdade, entre outras, é preciso "considerar a educação intercultural como um princípio orientador, teórica e praticamente, dos sistemas educacionais na sua globalidade" (CANDAU, 2002, p. 51), incluindo, aí, a formação de professores.

Também para Pansini e Nenevé (2008, p. 31-32)

[...] é impossível pensar numa educação multicultural sem que nos questionemos sobre o professor e sua formação. Para que se possa questionar o modo como a escola tem legitimado certos saberes apagando de seu currículo ou afastando do seu cotidiano as práticas pertencentes à cultura dos grupos subalternos é necessário investir, de maneira enfática, numa formação pedagógica multiculturalmente orientada que resista às tendências homogeneizadoras que permeiam as políticas educacionais atuais. Para tanto a formação precisa desenvolver nos sujeitos a capacidade de questionar os conhecimentos e práticas legitimadas [...]. Além do mais, destaca-se a necessidade de uma formação que permita aos educadores e educadoras reverem o uso da linguagem no espaço escolar uma vez que, é por meio da linguagem, entendida como prática humana social culturalmente organizada, que se torna possível, para professores e alunos, conhecerem o seu mundo mais próximo.

Atuar na profissão docente representa exercer a profissão em um contexto complexo e diversificado, que não significa apenas "transmissão do conhecimento ou transformação do conhecimento comum", mas requer uma nova formação inicial e continuada, pois a "profissão docente exerce outras funções: motivação, luta contra a exclusão social, participação, animação de grupos, relações com estruturas sociais, com a comunidade..." (IMBERNÓN, 2004, p. 14). Nesse sentido, o autor defende uma formação que valorize os múltiplos saberes, aliados ao ambiente educativo propício à manifestação das diferenças e que contribui para a atuação mais coerente com a educação necessária atualmente.

Segundo Pansini e Nenevé (2008), a formação inicial de professores é um espaço fundamental para a valorização e problematização das diferenças no espaço escolar e, nesse sentido

[...] os currículos das universidades devem priorizar a reflexão por parte dos futuros educadores sobre sua identidade, sobre os saberes locais específicos e ainda sobre como a linguagem pode agir como um fator de silenciamento das culturas minoritárias e locais, buscando compreender as relações entre conhecimento escolar, cultura e linguagem. Articulando a discussão em torno do multiculturalismo crítico com a formação de professores, os autores argumentam que uma formação multiculturalmente orientada deve ser o resultado da combinação das 
dimensões pedagógica, política e cultural de modo que se possa criar condições e instrumentos que permitam aos futuros educadores atuarem como profissionais reflexivos e comprometidos em romper com as práticas monoculturais presentes no cotidiano escolar. (PANSINI; NENEVÉ, 2008, p. 31).

Essa formação deve, também, oferecer ao professor subsídios que o auxiliem a construir estratégias de atuação que não gerem conflitos ou frustrações, de forma que possa permanecer motivado para realizar seu trabalho, com baixo nível de mal-estar no trabalho.

Imbernón (2004) destaca a importância de uma formação que possibilite a transcendência no ensino, que se transforme em possibilidades de criação de "espaços de participação, reflexão e formação para que as pessoas aprendam e se adaptem para poder conviver com a mudança e a incerteza" (IMBERNÓN, 2004, p. 15).

Pode-se entender, assim, a formação de professores como uma peça chave ao se discutir os desafios atuais do trabalho docente. E, embora esses desafios não se relacionem apenas às questões interculturais, pois deve-se considerar, também, as questões das novas tecnologias etc., percebe-se o quanto os professores precisam de novos conhecimentos para atuarem de maneira adequada e competente frente às novas exigências e configurações da sociedade contemporânea, incluindo-se, aí, a questão das diferenças.

Esse conjunto de elementos imbricados na concretização da educação intercultural, ao serem planejados e executados adequadamente, especialmente ao que diz respeito às formações inicial e continuada, podem auxiliar no enfrentamento dos desafios colocados aos professores. Coppete (2012, p. 162) reitera

[...] a relevância de se considerar cada vez mais e com maior profundidade não somente a cultura erudita e seus elementos no cenário da educação contemporânea, mas todas as culturas. E isso é de fundamental importância porque entre outros fatores reverbera nos significados e sentidos da docência na atualidade, assim como nas demandas que são geradas no interior das instituições educativas, especialmente nas escolas, e fundamentalmente no interior das salas de aula, caracterizando-se como intensos desafios à própria docência.

Muitos estudos, entre eles os de Moran (1994), Hernandez e Caldas (2001), Fried (2005), mostram que toda demanda exige uma mudança e um esforço de adaptação. E afirmam, ainda, que toda mudança provoca resistência, na medida em que o novo provoca insegurança, medo, exige desconstruções e reconstruções de esquemas enrijecidos, exige que se refaçam conceitos e esquemas cognitivos, exige vencer a resistência ao novo e colocar em prática um vai-e-vem de pensamentos e ações, exige esforço e dispêndio de energia. Assim, os professores devem estar motivados e preparados (intelectual/cognitiva e emocionalmente) para realizar esse esforço e despender a energia necessária para mudarem no sentido de concretizarem, de fato, uma educação intercultural.

\section{CONSIDERAÇÕES FINAIS}

[...] temos o direito a ser iguais
quando a nossa diferença nos
inferioriza; e temos o direito a ser
diferentes quando a nossa igualdade
nos descaracteriza. Daí a necessida-
de de uma igualdade que reconheça
as diferenças e de uma diferença que
não produza, alimente ou reprodu-
za as desigualdades.
(SANTOS, 2003, p. 56).

Perceber a educação em seu sentido amplo, intercultural, é de fundamental importância para o sucesso do processo 
de ensino e aprendizagem, da educação e da própria sociedade. Diante da grande diversidade, faz-se necessário que pessoas e grupos de culturas diferentes relacionem-se para o desenvolvimento e evolução da sociedade. A educação é uma importante contribuição para seja possível uma mudança por uma sociedade que discuta as diferenças culturais, levando-se em conta o necessário reconhecimento da legitimidade das diferentes culturas. Para tanto, é imprescindível haver, no âmbito escolar, espaço para discussão e estudos de temas que envolvam questões interculturais, uma vez que as diferenças, muitas vezes, geram tensões e conflitos.

O grande desafio da escola prevê um trabalho com a diversidade, ou seja, uma escola que se proponha a atuar de forma ativa com a heterogeneidade, que caminhe na perspectiva do diálogo, que considere relevante o 'outro', que valorize o diferente.

É possível constatar um avanço, na escola atual, no que diz respeito a essa temática, uma vez que já se percebe a presença de discussões acerca de gênero, sexualidade, relações étnico-raciais, tensões entre igualdade e diferenças e Direitos Humanos. Mas, para que se construa essa escola que seja, de fato, realizadora/ promotora de uma educação intercultural, muitos desafios deverão ser vencidos.

Para enfrentar esses desafios, tanto a escola, instituição social e local de trabalho do professor, como o próprio professor, ao realizar seu trabalho, deverão fortalecer os diálogos e as negociações no sentido de viabilizar a compreensão e o entendimento do processo de construção das diferenças dentro da diversidade cultural presentes em sociedades plurais, na tentativa de superar preconceitos culturais, além da apropriação das reivindicações e das lutas por reconhecimento da diferença e da cultura empreendida pelos movimentos sociais e, principalmente, (re)conhecer o 'outro' e respeitá-lo como sujeito nesse espaço intercultural.
Também deverão ser oferecidas formações que preparem os professores para trabalhar com a diversidade, com a escola heterogênea, que estejam preparados (intelectual/cognitiva e emocionalmente) para realizar as mudanças necessárias e enfrentar os desafios inerentes ao novo.

São grandes os desafios para a escola e para os professores mas também percebe-se um aumento nas investigações sobre essa temática que mostram maior interesse e sensibilidade sobre a questão intercultural no âmbito das escolas. Mas, para que esses estudos possam ser incorporados e traduzidos em práticas cotidianas nas escolas é preciso um trabalho conjunto de todos os atores do sistema educacional.

Há, implicados nos processos da educação intercultural, tanto elementos estratégicos, estruturais, tecnológicos, políticos e de controle como elementos da dimensão humana e cultural. Não se pode desconsiderar nenhum desses elementos com o risco de tornar infrutíferos todos os esforços empreendidos na direção de se concretizar ações educacionais que, de fato, concretizem uma educação que considere e respeite todas as diferenças presentes no âmbito escolar.

\section{REFERÊNCIAS}

CANDAU, V. M. Diferenças culturais, cotidiano escolar e práticas pedagógicas. Currículo sem Fronteiras, v. 11, n. 2, p. 240-255, 2011.

Direitos humanos, educação e interculturalidade: as tensões entre igualdade e diferença. In: CANDAU, V. M. (Org.). Educação intercultural na América Latina: entre concepções, tensões e propostas. Rio de janeiro: 7 Letras, 2009. p. 154-173.

A diferença está no chão da escola. In: COLÓQUIO LUSO-BRASILEIRO SOBRE QUESTÕES CURRICULARES, 4. E COLÓQUIOSOBRE QUESTÕES CURRICULARES, 8., 2008. Anais... Florianópolis: Universidade Federal de Santa Catarina, 2008.

. Sociedade, educação e cultura. Petrópolis, RJ: Vozes, 2002. 
COPPETE, M. C. Educação intercultural e sensibilidade: possibilidades para a docência. 2012. Tese (Doutorado em Educação) - Faculdade de Educação, Universidade Federal de Santa Catarina, Florianópolis, 2012.

FLEURI, R. M. Intercultura e educação. Revista Brasileira de Educação, n. 23, p. 16-35, 2003.

FLEURI, R. M. (Org.). Intercultura: estudos emergentes. Ijuí, RS: Unijuí, 2002.

FRIED, R. L. The game of school. New York: Jossey-Bass, 2005.

GABRIEL, C. T. Didática crítica multi/ intercultural: sobre interlocuções teóricas e construções de objetos. In: CANDAU, V. M. Educação intercultural e cotidiano escolar. Rio de Janeiro: 7Letras, 2006. p. 31-49.

GASPARIN, J. L. Uma didática para a pedagogia histórico-crítica. Campinas, SP: Autores Associados, 2007.

GRILLO, M. O professor e a docência: encontro com o aluno. In: ENRICONE, D. (Org.). Ser professor. Porto Alegre, RS: EDIPUCRS, 2004. p. 73-89.

HERNANDEZ, J. M. da C.; CALDAS, M. P. Resistência à mudança: uma revisão crítica. RAE - Revista de Administração de Empresas, São Paulo, v. 41, n. 2, p. 31-45, 2001.

IMBERNÓN, F. Formação docente e profissional: formar-se pra a mudança e a incerteza. 4. ed. São Paulo: Cortez, 2004.

JESUS, S. N. de. Professor sem stress. Realização e bem-estar docente. Porto Alegre, RS: Mediação, 2007.
Bem-estar dos professores: estratégias para realização e desenvolvimento profissional. Porto, Portugal: Porto Editora, 1998.

MORAN, E. F. Adaptabilidade humana. São Paulo: Edusp, 1994.

PANSINI, F.; NENEVÉ, M. Educação multicultural e formação docente. Currículo sem Fronteiras, v. 8, n. 1, p. 31-48, 2008.

PERUCCI, A. F. Ciladas da diferença. São Paulo: Editora 34, 1999.

SÁ, M. J. R. de; CORTEZ, D. de S. Desafios contemporâneos ao trabalho docente: mediações de saberes multi/interculturais no cotidiano educativo. In: ENCONTRO INTERNACIONAL DA SOCIEDADE BRASILEIRA DE EDUCAÇÃO COMPARADA, 5., 2012. Anais... Belém do Pará, 2012. Disponível em: <http://www.sbec.org.br/evt_2012.php>.

SANTOS, B. de S. Reconhecer para libertar: os caminhos do cosmopolitanismo multicultural. Rio de Janeiro: Civilização Brasileira, 2003.

SERPA, A. Cultura escolar em movimento: diálogos possíveis. Rio de Janeiro: Rovelle, 2011.

SILVA, S. R.; ALMEIDA, M. de L. P. de. Inclusão, reconhecimento e políticas educacionais no Brasil. In: NASCIMENTO, A. C.; LOPES, M. C. L. P.; BITTAR, M. (Org.). Relações interculturais no contexto da inclusão. Campinas, SP: Mercado de Letras, 2012. p. 19-38.

TARDIFF, M.; LESSARD, C. O trabalho docente: elementos para uma teoria da docência como profissão de interações humanas. Petrópolis, RJ: Vozes, 2011.

\section{Sobre as autoras:}

Vanilda Alves da Silva: Doutoranda em Educação no Programa de Pós-Graduação em Educação da Universidade Católica Dom Bosco (PPGE/UCDB). Professora da Universidade Federal de Mato Grosso do Sul (UFMS). E-mail: vanilda.ufms.pp@gmail.com

Flavinês Rebolo: Doutora em Educação. Professora do Programa de Pós-Graduação em Educação da Universidade Católica Dom Bosco (PPGE/UCDB). E-mail: flavines.rebolo@uol.com.br 